\title{
Counting on co-transcriptional splicing
}

\section{Mattia Brugiolo, Lydia Herzel and Karla M. Neugebauer*}

Address: Max Planck Institute of Molecular and Cellular Biology and Genetics, Pfotenhauerstrasse 108, 01309 Dresden, Germany The contribution of the first two authors is equal, and their names are listed alphabetically.

* Corresponding author: Karla M. Neugebauer (neugebau@mpi-cbg.de)

FI000Prime Reports 2013, 5:9 (doi:10.12703/P5-9)

This is an open-access article distributed under the terms of the Creative Commons Attribution-Non Commercial License (http://creativecommons.org/licenses/by-nc/3.0/legalcode), which permits unrestricted use, distribution, and reproduction in any medium, provided the original work is properly cited. You may not use this work for commercial purposes.

The electronic version of this article is the complete one and can be found at: http://fl000.com/prime/reports/b/5/9

\begin{abstract}
Splicing is the removal of intron sequences from pre-mRNA by the spliceosome. Researchers working in multiple model organisms - notably yeast, insects and mammalian cells - have shown that pre-mRNA can be spliced during the process of transcription (i.e. co-transcriptionally), as well as after transcription termination (i.e. post-transcriptionally). Co-transcriptional splicing does not assume that transcription and splicing machineries are mechanistically coupled, yet it raises this possibility. Early studies were based on a limited number of genes, which were often chosen because of their experimental accessibility. Since 2010, eight studies have used global datasets as counting tools, in order to quantify co-transcriptional intron removal. The consensus view, based on four organisms, is that the majority of splicing events take place co-transcriptionally in most cells and tissues. Here, we discuss the nature of the various global datasets and how bioinformatic analyses were conducted. Considering the broad differences in experimental approach and analysis, the level of agreement on the prevalence of co-transcriptional splicing is remarkable.
\end{abstract}

\section{Introduction}

Transcription and pre-mRNA splicing are carried out by two distinct macromolecular machines, RNA polymerase II (Pol II) and the spliceosome, which are capable of functioning independently of one another. Polyadenylation of transcripts occurs upon co-transcriptional cleavage of the nascent RNA chain and, thereby, indicates that transcription is complete. Although most mature poly A+ transcripts are spliced, early studies yielded mixed results as to whether splicing is completed before polyadenylation [1-3]. Subsequently, a number of key studies in several model systems supported the notion that splicing at least begins co-transcriptionally, i.e. on nascent RNA tethered to chromatin by elongating Pol II [4-12]. Co-transcriptional splicing is not surprising: nucleoplasm is filled with spliceosomal components that should be able to associate with nascent RNA, much as ribosomes are capable of translating RNA co-transcriptionally in bacteria. Moreover, in vivo rates for the splicing reaction are fast: in the order of 30 seconds to 3 minutes from the time the intron is complete, depending on the species and the method used [5,12-15]; splicing takes significantly less time than gene transcription [16]. Nevertheless, some dramatic examples of post-transcriptional splicing - for example, in anucleate platelets upon activation and in developing fern gametes - remind us of the potential importance of not splicing co-transcriptionally in certain biological contexts $[17,18]$.

The regulatory potential of co-transcriptional splicing is what the field has found so exciting. We started to consider the possibilities that Pol II and the spliceosome could interact physically, that transcription might influence splicing and vice versa, and that co-transcriptional RNA processing could yield a more "fit" mRNP $[16,19]$. We asked ourselves: how frequent is co-transcriptional splicing among genes and introns? Early studies were based on specific genes, which were handpicked because 
of special properties such as transcriptional inducibility, gene length, and accessibility to light and/or EM microscopy [20]. Since 2010, eight global studies, investigating multiple tissues and cell types in four organisms, have been published. The consensus view is that co-transcriptional splicing is widespread (see Table 1). These important studies are the subject of this review.

\section{Global studies of co-transcriptional splicing}

The first global study on co-transcriptional splicing was undertaken in budding yeast, where it became clear that most introns are spliced co-transcriptionally; $50 \%$ of introns are $>74 \%$ spliced before transcription termination [21]. Table 1 shows that co-transcriptional splicing frequencies are similarly high in fly and human cell lines and tissues [22-26]. Despite general agreement, there are important experimental and analytical differences among the studies. Carrillo Oesterreich et al. [21], Khodor et al. $[23,27]$ and Tilgner et al. [24] all based their analyses on RNA isolated from biochemically purified chromatin, whereas Ameur et al. [22] and Windhager et al. [25] used total RNA sequencing and 4-thio-uridine (4sU)-labeling, respectively, to quantify co-transcriptional splicing. Even active spliceosomes and their nuclear location can be monitored, using protein biochemistry and immunofluorescence, showing that the majority of active spliceosomes is associated with chromatin [26]. That said, not all intron removal is co-transcriptional. In particular, terminal introns are least well removed co-transcriptionally, and $20 \%$ of activated spliceosomes in the cell are not chromatin-associated $[24,26]$.

Table 1 and Figure 1 illustrate the key points of each global study and how co-transcriptional splicing frequencies were quantified. Due to different sample preparations and RNA pools analyzed, one can rarely apply the same method of analysis to a given dataset. For example, Ameur et al. performed total RNA sequencing; because exon reads could come from nascent or mature RNA, analysis was restricted to intron reads [22]. Gene architecture differences (e.g. short and few introns in yeast versus long and many introns in humans) also play a role. Three modes of analysis have been employed, using either junction reads reads representing spliced (exon-exon) and unspliced (exon-intron and intron-exon) - or intron and/or exon coverage for calculating a splicing score:

1. Exon-centered splicing score $[22,24]$. Pro: Optimal for alternative cassette exon usage. Con: First and terminal exons have to be analyzed differently.

2. Intron-centered splicing score $[21,23,27]$. Pro: First and terminal exons can be included in the analysis. Con: Short exons are a disadvantage.
3. Gene-based splicing score $[24,28]$. Pro: Inclusion of many reads reduces noise. Con: No independent splicing values for individual introns; no information about alternative splicing events per gene; stable RNAs encoded within introns artificially lower splicing, if not filtered out; because RNAseq data are often biased towards 3 ' ends, results could depend on transcript length.

Differences among the methods could well influence the numerical results obtained and/or the interpretations, sometimes making it hard to compare the studies. For example, intron length negatively correlates with co-transcriptional splicing frequency in Drosophila, mouse and human cells [23,24,27]. However, Ameur et al., focusing their analysis in human brain on highly expressed genes with long introns, conclude the opposite [22]. Experimental validation of RNA sequencing and array data by RT-qPCR strengthens and extends results from these approaches $[21,22]$. Though Ameur et al. could not calculate co-transcriptional splicing frequencies for short introns genome-wide, their RT-PCR results suggest that high co-transcriptional splicing observed for long introns can also be inferred for shorter ones [22]. Remarkably, numerous studies agree that constitutive splicing is more co-transcriptional than alternative splicing [22-24,27].

Last year, one study conducted in induced mouse macrophages reported that full-length, polyA cleaved RNAs accumulate on chromatin in a partially spliced state [28]. The inference that splicing is completed posttranscriptionally in this cell type has been rather hastily interpreted as evidence against co-transcriptional splicing in general $[29,30]$. However, no overall numerical values for co-transcriptional splicing are provided [28]. Direct comparison to the other global studies is more difficult, because this analysis calculates splicing values on a per gene basis, using coverage over the whole gene (see Table 1 and Figure 1); since splicing values vary from intron to intron (see above), calculations for individual splicing events are more informative. It is possible that the gene-based frequency of splicing yields an underestimate of intron removal; for example, summation of the coverage data from Tilgner et al. (see Table S2 in [24]) also yields a lower co-transcriptional splicing frequency than usage of splice junction reads (Table 1) [24]. Introns contain a number of stable RNAs, such as snoRNAs, which contribute reads that do not represent unspliced transcripts [31]. Gene-based calculations may be influenced by coverage biases that can reflect differences in nucleotide content (e.g. fraction GC), directionality of sequencing (e.g. from the $3^{\prime}$ end) or RT-priming, which all influence the preparation of RNAseq libraries [32]. The average co-transcriptional 


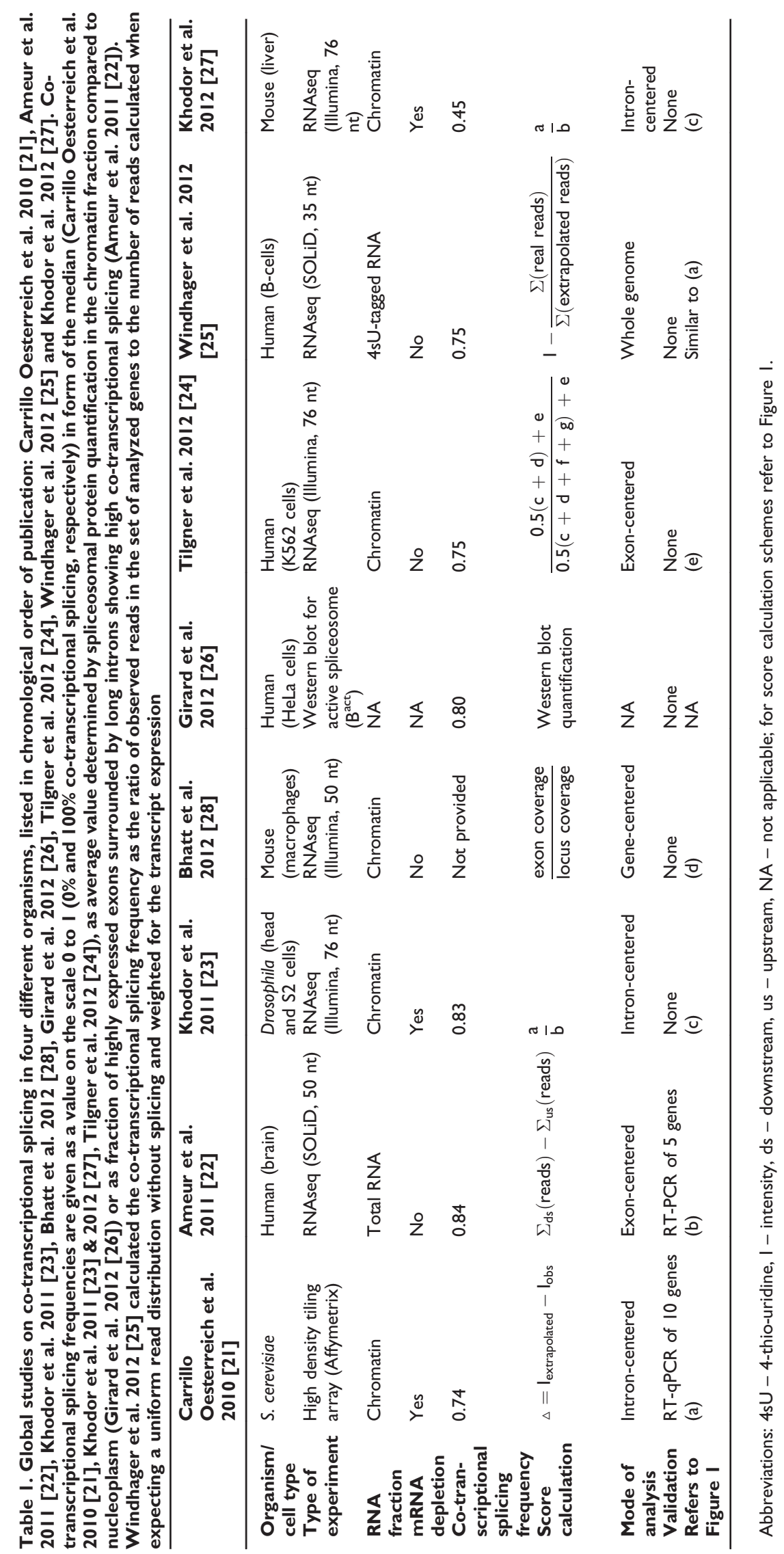


Figure I. Schematic representations of how co-transcriptional splicing scores are calculated in global studies

(a)
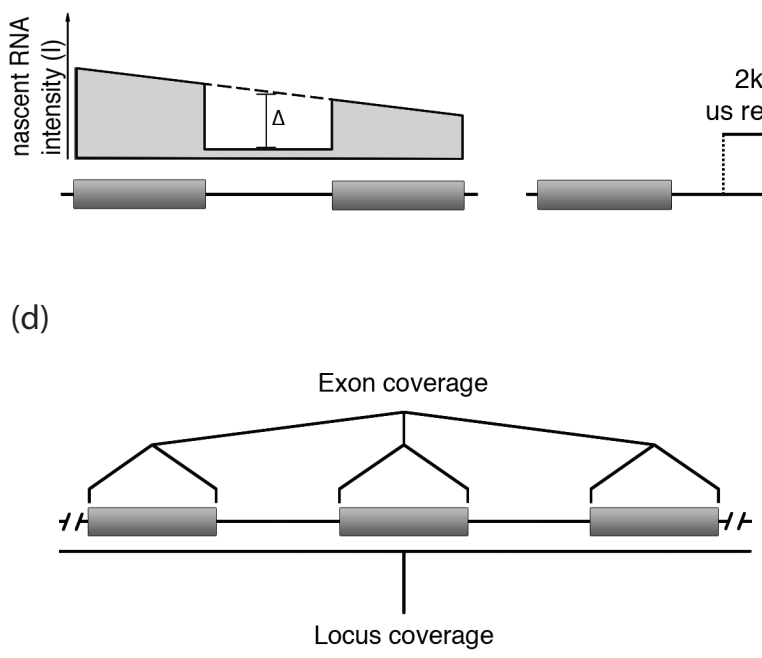

(d) (b)

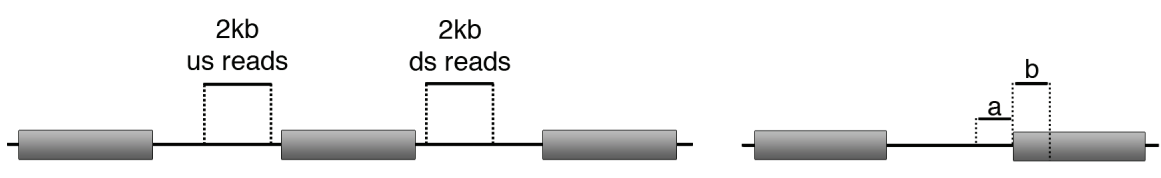

(e) (c)

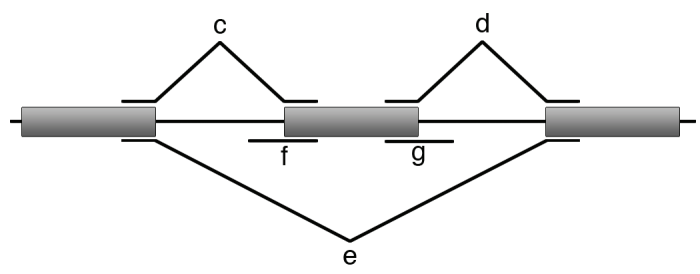

(a) Calculation of co-transcriptional splicing frequency $(\Delta)$ for each intron, by determining the relative difference between observed and extrapolated intronic probe intensities, using high density tiling arrays. (b) Determination of co-transcriptional splicing frequency around a given exon, by subtracting the read coverage over $2 \mathrm{~kb}$ of the upstream intron ( $\left.\sum_{\mathrm{us}}\right)$ from read coverage over $2 \mathrm{~kb}$ of the 5 ' end of the downstream intron ( $\left.\sum_{\mathrm{ds}}\right)$. (c) Determination of cotranscriptional splicing frequency for each intron, by calculating the ratio of reads around the 3 ' splice site: read coverage over the last 25 bp of a given intron, a, is divided by read coverage over the first 25 bp of the downstream exon, b. (d) Determination of co-transcriptional splicing frequency for each gene, by dividing the read coverage over exons by the read coverage over the whole locus. (e) Determination of co-transcriptional splicing frequency (completed splicing index, coSI) around a given exon, using exon-intron and exon-exon junction reads; $\mathbf{c}, \mathbf{d}$, and e represent exon-exon junctions; $\mathbf{f}$ and $\mathbf{g}$ represent exonintron junctions.

splicing frequencies obtained for each gene will likely be influenced by gene length and the total number of introns within the gene; terminal exons are long and generally full of reads, and terminal introns tend to be least well spliced co-transcriptionally $[6,11,24]$. Nevertheless, it is clear from this and previous studies (referenced within) that processing may be delayed in these cells, such that a higher proportion of splicing is post-transcriptional. It would be fascinating to know which introns are being retained and, indeed, whether all introns within the same transcript are retained. The relatively low co-transcriptional splicing frequencies from both mouse studies contrast sharply with the high co-transcriptional splicing frequencies from yeast, fly, and human (Table 1). Perhaps the easiest means of addressing this would be to analyze directly comparable human and mouse cell types.

It is difficult to resolve differences among studies when validation of co-transcriptional splicing frequencies by an independent method, such as RT-PCR, is omitted. Unfortunately, most current studies do not include validation. Validation acknowledges that something can be unexpected in either the experiment or the analysis, such as differences in biochemical purification, library biases or genome annotation [32]. For example, chromatin preparations can be contaminated with mRNA, which is highly abundant and could lead to an over-estimate in the degree of co-transcriptional splicing. A co-transcriptional process is one that occurs before polyA cleavage, so one would ideally like to incorporate this property into the validation. Due to fluctuations in read densities, the degree of polyA cleavage in the RNA sample can be difficult to ascertain from RNAseq. A prominently used assay employs reverse transcription to specifically copy only uncleaved transcripts, by utilizing a reverse primer placed downstream of the polyA cleavage site; subsequent PCR can query the spliced or unspliced status of the nascent RNA $[11,12,21,33]$. This method can be difficult in mammals, where polyA cleavage sites are hard to predict. Nevertheless, an independent, small-scale study focusing on 22 human genes was able to validate the high frequencies of co-transcriptional splicing seen in the global data, even among terminal and alternative introns [12].

\section{Summary and future directions}

Taken together, this array of high quality global studies enables us to reach a consensus on co-transcriptional 
splicing: it is widespread, albeit not 100\%. Future challenges encompass the relative importance of co- and post-transcriptional splicing in terms of the fate of the RNA, on the one hand, and/or transcriptional activity of the gene, on the other hand. For example, histone modifications, which would have a bearing on cotranscriptional but not post-transcriptional splicing, can directly or indirectly recruit splicing factors and modify alternative splicing [34,35]. Moreover, transcription elongation rates are influenced by nucleosome positioning and histone modifications, which influence alternative splice site choice $[16,35,36]$. Co-transcriptional splicing may also have long-lasting effects on the RNA's lifetime, by ensuring proper assembly of export-competent mRNPs [19]. These examples show that co-transcriptional splicing is important for mRNA biogenesis. Co-transcriptional splicing has also emerged as an important regulator of transcriptional activity. It has long been known that the presence of promoter-proximal introns can stimulate gene expression [37-39]. Recent work shows that splicing feeds back to transcription through a distance-dependent enhancer-like activity of the first 5' splice site [33].

Thus, genes and gene expression machinery have evolved coordinately to take advantage of crosstalk between transcription and splicing. If specific biological situations such as the activation of transcriptional programs in macrophages or the repression of splicing in platelets circumvent co-transcriptional processes, then perhaps there are additional regulatory reasons. In this sense, it is important to recognize that no study claims $100 \%$ of introns are 100\% co-transcriptionally removed. Advances in high-throughput sequencing that enable sequencing of longer DNA molecules (in the kilobase range) will provide clarity and facilitate analysis, as well as providing insight into the order of intron removal and co-transcriptional dynamics of alternative splicing. Those introns, such as alternative introns, that are spliced post-transcriptionally may be subject to different regulatory mechanisms $[19,40]$. A challenge for the future will be to more fully explore the significance of post-transcriptional splicing for gene expression.

\section{Abbreviations}

mRNP, messenger ribonucleoprotein; Pol II, RNA polymerase II; polyA, polyadenylation; RNAseq, highthroughput sequencing of cDNA libraries (Illumina); RT-PCR, reverse transcription polymerase chain reaction; RT-qPCR, reverse transcription - quantitative polymerase chain reaction.

\section{Disclosures}

The authors declare that they have no disclosures.

\section{Acknowledgements}

We thank members of our laboratory, Fernando Carrillo Oesterreich, Karen Adelman, Jean Beggs, and Thoru Pederson for helpful discussions and comments on the manuscript. Also, Mattia Brugiolo was supported by the EU FP7 ITN project RNPnet (contract number 289007).

\section{References}

I. Nevins J, DarnellJE: Steps in the processing of Ad2 mRNA: Poly(A)+ nuclear sequences are conserved and poly(A) addition precedes splicing. Cell 1978, I5: 1477-93.

2. Tilghman SM, Curtis PJ, Tiemeier DC, Leder P, Weissmann C: The intervening sequence of a mouse beta-globin gene is transcribed within the $15 \mathrm{~S}$ beta-globin mRNA precursor. Proc Natl Acad Sci USA 1978, 75:1309-13.

3. LeMeur M, Glanville N, Mandel JL, Gerlinger P, Palmiter R, Chambon $P$ : The ovalbumin gene family: hormonal control of $X$ and $Y$ gene transcription and mRNA accumulation. Cell 198I, 23:56|-7|.

4. Osheim YN, Miller OL, Beyer AL: RNP particles at splice junction sequences on Drosophila chorion transcripts. Cell 1985, 43:|43-5I.

\section{FIOOOPrime}

RECOMMENDED

5. Beyer AL, Osheim YN: Splice site selection, rate of splicing, and alternative splicing on nascent transcripts. Genes \& Development 1988, 2:754-65.

FlOOOPrime RECOMMENDED

6. Zhang G, Taneja KL, Singer RH, Green MR: Localization of premRNA splicing in mammalian nuclei. Nature 1994, 372:809-12.

\section{FlOOOPrime}

\section{RECOMMENDED}

7. Baurén G, Wieslander L: Splicing of Balbiani ring I gene premRNA occurs simultaneously with transcription. Cell 1994, 76: $183-92$.

8. Wetterberg I, Baurén G, Wieslander L: The intranuclear site of excision of each intron in Balbiani ring 3 pre-mRNA is influenced by the time remaining to transcription termination and different excision efficiencies for the various introns. Rna 1996, 2:64I-5I.

\section{FIOOOPrime}

\section{RECOMMENDED}

9. Singh J, Padgett RA: Rates of in situ transcription and splicing in large human genes. Nat Struct and Mol Biol 2009, 16:1 I 28-33.

\section{FlOOOPrime}

RECOMMENDED

10. Wada $Y$, Ohta $Y, X u$ M, Tsutsumi S, Minami T, Inoue K, Komura D, Kitakami J, Oshida N, Papantonis A, et al.: A wave of nascent transcription on activated human genes. Proc Natl Acad Sci USA 2009, 106: |8357-6|.

FlOOOPrime RECOMMENDED

II. Pandya-Jones A, Black DL: Co-transcriptional splicing of constitutive and alternative exons. Rna 2009, 15:1896-908.

\section{FlOOOPrime}

RECOMMENDED

12. Schmidt U, Basyuk E, Robert MC, Yoshida M, Villemin JP, Auboeuf D, Aitken S, Bertrand E: Real-time imaging of cotranscriptional splicing reveals a kinetic model that reduces noise: implications for alternative splicing regulation. J Cell Biol 20II, 193:819-29. 
13. Lacadie S: In vivo commitment to yeast cotranscriptional splicing is sensitive to transcription elongation mutants. Genes \& Development 2006, 20:2055-66.

\section{FIOOOPrime}

\section{RECOMMENDED}

14. Alexander RD, Barrass JD, Dichtl B, Kos M, Obtulowicz T, Robert MC, Koper M, Karkusiewicz I, Mariconti L, Tollervey D, et al.: RiboSys, a high-resolution, quantitative approach to measure the in vivo kinetics of pre-mRNA splicing and 3'-end processing in Saccharomyces cerevisiae. Rna 2010, 16:2570-80.

\section{FlOOOPrime} RECOMMENDED

15. Huranová M, Ivani I, Benda A, Poser I, Brody Y, Hof M, Shav-Tal Y, Neugebauer KM, Stanek D: The differential interaction of snRNPs with pre-mRNA reveals splicing kinetics in living cells. J Cell Biol 2010, 191:75-86.

16. Carrillo Oesterreich F, Bieberstein N, Neugebauer KM: Pause locally, splice globally. Trends in Cell Biology 20 I , I-8.

17. Denis MM, Tolley ND, Bunting M, Schwertz H, Jiang $H$, Lindemann S, Yost CC, Rubner FJ, Albertine KH, Swoboda KJ, et al:: Escaping the nuclear confines: signal-dependent pre-mRNA splicing in anucleate platelets. Cell 2005, 122:379-9I.

\section{FIOOOPrime}

18. Boothby TC, Zipper RS, van der Weele CM, Wolniak SM: Removal of Retained Introns Regulates Translation in the Rapidly Developing Gametophyte of Marsilea vestita. Dev Cell 20I 3, 24: [Epub ahead of print]

\section{FIOOOPrime}

19. Han J, Xiong J, Wang D, Fu XD: Pre-mRNA splicing: where and when in the nucleus. Trends in Cell Biology 2011, 21:336-43.

20. Pandya-Jones A: Pre-mRNA splicing during transcription in the mammalian system. WIREs RNA 20II, 2:700-17.

21. Carrillo Oesterreich F: Global Analysis of Nascent RNA Reveals Transcriptional Pausing in Terminal Exons. Mol Cell 2010, 40:57I-8I.

\section{FIOOOPrime}

\section{RECOMMENDED}

22. Ameur A, Zaghlool A, Halvardson J, Wetterbom A, Gyllensten U, Cavelier L, Feuk L: Total RNA sequencing reveals nascent transcription and widespread co-transcriptional splicing in the human brain. Nat Struct and Mol Biol 20I I, 18:1435-40.

\section{FlOOOPrime RECOMMENDED}

23. Khodor Y, Rodriguez J, Abruzzi K, Tang C, Marr M, Rosbash M: Nascent-seq indicates widespread cotranscriptional premRNA splicing in Drosophila. Genes \& Development 201I, 25:2502-12

\section{FlOOOPrime}

24. Tilgner H, Knowles D, Johnson R, Davis C, Chakrabortty S, Djebali S, Curado J, Snyder M, Gingeras T, Guigo R: Deep sequencing of subcellular RNA fractions shows splicing to be predominantly co-transcriptional in the human genome but inefficient for IncRNAs. Genome Res 2012, 22:1616-25.

\section{FlOOOPrime RECOMMENDED}

25. Windhager L, Bonfert T, Burger K, Ruzsics Z, Krebs S, Kaufmann S, Malterer G, L'hernault A, Schilhabel M, Schreiber S, et al.: Ultrashort and progressive 4sU-tagging reveals key characteristics of
RNA processing at nucleotide resolution. Genome Res 2012, 22:203।-42.

FlOOOPRime
RECOMMENDED

26. Girard C, Will C, Peng J, Makarov E, Kastner B, Lemm I, Urlaub H, Hartmuth K, Lührmann R: Post-transcriptional spliceosomes are retained in nuclear speckles until splicing completion. Nat Comms 2012, 3:994.

\section{FlOOOPrime}

\section{RECOMMENDED}

27. Khodor Y, Menet J, Tolan M, Rosbash M: Cotranscriptional splicing efficiency differs dramatically between Drosophila and mouse. Rna 20I2, 18:2174-86.

28. Bhatt DM, Pandya-Jones A, Tong A, Barozzi I, Lissner MM, Natoli G, Black DL, Smale ST: Transcript dynamics of proinflammatory genes revealed by sequence analysis of subcellular RNA fractions. Cell 2012, 150:279-90.

\section{FlOOOPrime}

\section{RECOMMENDED}

29. Sen R, Fugmann SD: Transcription, splicing, and release: are we there yet? Cell 20I2, I50:24I-3.

30. Stower H: Splicing: Waiting to be spliced. Nat Rev Genet 20I2, 13:599.

3I. St Laurent G, Shtokalo D, Tackett MR, Yang Z, Eremina T, Wahlestedt C, Urcuqui-Inchima S, Seilheimer B, McCaffrey TA, Kapranov P: Intronic RNAs constitute the major fraction of the non-coding RNA in mammalian cells. BMC Genomics 2012, 13:504.

32. Plocik A, Graveley B: New Insights from Existing Sequence Data: Generating Breakthroughs without a Pipette. Mol Cell 20I3, 49:605-I7.

33. Bieberstein NI, Carrillo Oesterreich F, Straube K, Neugebauer KM: First Exon Length Controls Active Chromatin Signatures and Transcription. Cell Reports 2012, 2:62-8.

34. Luco RF, Allo M, Schor I, Kornblihtt A, Misteli T: Epigenetics in Alternative Pre-mRNA Splicing. Cell 20II, 144:16-26.

\section{FIOOOPRime
RECOMMENDED}

35. Kornblihtt A, Schor I, Alló M, Dujardin G, Petrillo E, Muñoz MJ: Alternative splicing: a pivotal step between eukaryotic transcription and translation. Nature Reviews Molecular Cell Biology 2013, 14:153-65

36. Gómez Acuña L, Fiszbein A, Alló M, Schor I, Kornblihtt A: Connections between chromatin signatures and splicing. WIREs RNA 20I3, 4:77-91.

37. Brinster RL, Allen JM, Behringer RR, Gelinas RE, Palmiter RD: Introns increase transcriptional efficiency in transgenic mice. Proc Natl Acad Sci USA 1988, 85:836-40.

\section{FlOOOPrime
RECOMMENDED}

38. Furger A, O'Sullivan JM, Binnie A, Lee BA, Proudfoot NJ: Promoter proximal splice sites enhance transcription. Genes \& Development 2002, 16:2792-9.

\section{FlOOOPRime
RECOMMENDED}

39. Rose A: The effect of intron location on intron-mediated enhancement of gene expression in Arabidopsis. The Plant Journal 2004, 40:744-5I.

40. Vargas D, Shah K, Batish M, Levandoski M, Sinha S, Marras S, Schedl P, Tyagi S: Single-Molecule Imaging of Transcriptionally Coupled and Uncoupled Splicing. Cell 20I I, I47:1054-65. 